http://jmscr.igmpublication.org/home/ ISSN (e)-2347-176x ISSN (p) 2455-0450 crossref DOI: https://dx.doi.org/10.18535/jmscr/v7i7.159

Journal Of Medical Science And Clinical Research

\title{
Prevalence of dry eye disease among individuals with diabetes mellitus attending out-patient department of a tertiary care hospital
}

\author{
Authors \\ Vijender Kour ${ }^{1}$, Shiraz Ahmad Bhat ${ }^{2 *}$, Harvinder Kour ${ }^{3}$ \\ ${ }^{1}$ (MS) Senior Resident, Department of Ophthalmology, ASCOMS, Jammu \\ ${ }^{2}$ (DO, DNB) Mohanlal Memorial Gandhi Eye Hospital, Aligarh \\ ${ }^{3}$ Intern Scholar, Government Medical College, Srinagar \\ *Corresponding Author \\ Shiraz Ahmad Bhat \\ Mohanlal Memorial Gandhi Eye Hospital Aligarh
}

\begin{abstract}
Background: Diabetes mellitus being one of the systemic diseases which affects almost every system of our body and may cause multiple complications.

Objectives: To estimate prevalence and clinical characteristics of DED among diabetic patients.

Methods: All the diabetic patients attending the out-patient unit of Postgraduate department of Ophthalmology, Government Medical College \& Associated SMHS Hospital who gave written informed consent and willingly participated in the study were included in the study. Socio-demographic data, clinical data pertaining to diabetes symptoms, duration of disease, presenting illness and other co-morbid conditions was collected using a pre-designed, pre-tested structured questionnaire. All the study participants were subjected to visual acuity test and slit-lamp examination. DED was confirmed by tear film break up time (TBUT) and Schirmer's I test. Diagnosis was established by positivity of one or both the tests (TBUT or Schirmer's test).

Results: The studied individuals were between the age ranges of 40-79 years with mean age of $56 \pm 13.6$ years. Among the studied sample, 49 (54.4\%) were females, 36(40\%) were doing elementary jobs while the educational status of most of the patients, 42(46.6\%) was intermediate/diploma holders. Majority of the studied patients 34 (37.8\%) belonged to Upper middle (II) class. Among the patients 31 (34.4\%) were having moderate type retinopathy on fundoscopy examination, majority 45(50\%) had thin tear meniscus height. In our study, a total of 47(52.2\%) patients had dry eyes which was further classified into mild 21(23.3\%), moderate 16(17.8\%) and severe 10(11.1).

Conclusion: Dry eye disease is a common entity among individuals with diabetes mellitus and the estimated prevalence of DED at our hospital is about $52 \%$.
\end{abstract}

\section{Introduction}

Diabetes mellitus is one of the emerging noncommunicable diseases which is nowadays a serious public health issue in many nations of the world. The last three decades have witnessed a growing number of diabetics all over the globe and the populations of diabetics has almost doubled $^{[1]}$. Diabetes mellitus being one of the systemic diseases which affects almost every system of our body and may cause multiple complications. In this paper, we would like to focus on dry eye disease (DED) which is one of 
the ocular complications most common among the individuals living with diabetes (ILD). Other common complications include chronic inflammation of the lid, acute orbital infection ptosis, hordeolosis, cataract, keratopathy, diabetic retinopathy and glaucoma ${ }^{[2]}$. "DED is defined as an abnormality in the quality or quantity of tears or in tear dynamics due to any cause, resulting in ocular discomfort, visual disturbance, decreased tear film stability, and potential damage to the ocular surface ${ }^{[3]}$." The occurrence of DED among individuals living with diabetes has been reported by many researchers in the past. The mechanism responsible for dry eye in DM is unclear, but autonomic dysfunction may be responsible ${ }^{[4]}$.

The prevalence of DED have been reported more among diabetics than the healthy individuals. Symptoms like burning and foreign body sensation, itching are frequently reported by individuals living with diabetes ${ }^{[5]}$. A study suggests that individuals with type 2 diabetes are more likely to suffer from tear film dysfunction ${ }^{[6]}$, while another study reported a higher prevalence of DED (54.3\%) among diabetic individuals when compared with non-diabetic individuals ${ }^{[7]}$. Furthermore, an association of age, sex, duration of diabetes and other associated complications was found to have positive association with $\mathrm{DED}^{[7]}$. Another study also reported a significant correlation of DED with glycosylated hemoglobin (HbA1c) values ${ }^{[8]}$.

However, all of the published epidemiological studies on DED among individuals living with type 2 diabetic mellitus have been reported from all over the world. As per our knowledge no such study documenting prevalence of DED and its risk factors among Kashmiri population have been documented. In the present study, we examined the prevalence and clinical characteristics of DED among patients attending an out-patient department of one of the biggest tertiary care hospitals of Kashmir valley. The study will enhance early detection of DED among individuals with diabetes and prevent further progression of disease among them.

\section{Methods}

Study Design: Cross-sectional study consisting of 90 individuals living with diabetes (Type 2 diabetes mellitus).

Study Setting: Out-patient unit of Postgraduate department of Ophthalmology, Government Medical College \& Associated SMHS Hospital, Srinagar, Kashmir.

Study Unit: Individuals living with diabetes who attended the out-patient unit of the said hospital with any of the eye related problems. Study Period: 18 Months (April 2017-October 2018). Sample Size: $90 \quad 69 \%$ prevalence ${ }^{[4]}, 10 \%$ precision sample size -82 , Non-response rate of $10 \%$. Final sample=90).

Sampling Method: Non-probability sampling (purposive sampling).

Inclusion Criteria: All the diabetic patients attending the out-patient unit of Postgraduate department of Ophthalmology, Government Medical College \& Associated SMHS Hospital who gave written informed consent and willingly participated in the study. Both genders, age $>40$ years old.

Exclusion Criteria: History of any ocular surgery, contact lens users, any ocular disease other than diabetes which can cause DED, any systemic or local medication user known to cause DED.

Method of Data Collection: The study was conducted among individuals living with Type 2 diabetes mellitus who attended the out-patient unit of postgraduate department of ophthalmology, Government medical college and associated SMHS hospital for any eye ailment. Written informed consent was obtained from each individual who satisfied the inclusion criteria. The participants were explained the objectives of the study. Socio-demographic data, clinical data pertaining to diabetes symptoms, duration of disease, presenting illness and other co-morbid conditions was collected using a pre-designed, pre-tested structured questionnaire. All the study participants were subjected to visual acuity test and slit-lamp examination. DED was confirmed 
by tear film break up time (TBUT) and Schirmer's I test. Diagnosis was established by positivity of one or both the tests (TBUT or Schirmer's test).

Statistical Analysis: Descriptive and inferential statistical analysis has been carried out in this study. Results on continuous measurements are presented on mean \pm standard deviation $\mathrm{D}$ (min$\max$ ) and results on categorical measurements are presented in number (\%). The significance is assessed at 5\% level of significance. Appropriate statistical tests have been used as and when required.

Ethical Issues: The study did not involve any issues pertaining to animal or human experimentation and had no ethical issues. The confidentiality of the participants was maintained and the data collect for the study was used only for research purposes.

\section{Tear film break up time}

Moistened with nonpreservative saline fluorescein strips (Omni Strips Fluro; Ophthalmic Strips U.S.P.) were introduced into the conjunctival sac with minimal stimulation, undetected by the patients. The individuals were then instructed to blink several times for a few seconds to ensure adequate mixing of fluorescein. The tear film was examined with a broad beam and a cobalt blue filter. The interval between the last complete blink and the appearance of the first corneal black spot or line in the stained tear film was measured using a stopwatch.A TFBUT value more than $10 \mathrm{~s}$ was considered normal, a value of $8-10 \mathrm{~s}$ was considered mild dryness, a value of 5-7 s was considered moderate dryness, and a value less than $5 \mathrm{~s}$ was considered severe dryness ${ }^{[4]}$.

\section{Schirmer's test}

This test measures tear secretion over a specified time. Schirmer test I without topical anesthesia (total tear secretion) was carried out with standardized strips. The strip was folded at the notch and placed at the junction of the middle and lateral thirds of the lower eyelids and allowed to stay in place for 5 min with patient's eyes gently closed. The filter paper was removed, and the amount of wetting was measured. More than 10 $\mathrm{mm}$ of wetting after 5 min was considered normal, 8-10 mm of wetting was considered mild dryness, 5-7 $\mathrm{mm}$ of wetting was considered moderate dryness, and less than $5 \mathrm{~mm}$ of wetting was considered severe dryness at the end of $5 \mathrm{~min}^{[4]}$.

\section{Results}

The study was conducted at the postgraduate department of ophthalmology, Government medical college, Srinagar among 90 diabetic individuals who attended the outpatient department of the said for any eye ailment. The studied individuals were between the age ranges of 40-79 years with mean age of $56 \pm 13.6$ years. Most of the patients (34.5\%) were in the age group of 61-70 years. Among the studied sample, $49(54.4 \%)$ were females, 36(40\%) were doing elementary jobs while 23(25.5\%) were skilled workers. The educational status of most of the patients, 42(46.6\%) was intermediate/diploma followed by high school pass 22(24.4\%). Majority of the studied patients belonged to Upper middle (II), 34 (37.8\%) and Lower Middle (III), 26 (28.9\%) as per Modified Kuppuswamy's socioeconomic scale update for $2019^{[9]}$ as shown in Table 1. Each patient was evaluated and eye examinations were performed. The funduscopy findings of the studied patients is described in table 2. Among the patients 31 (34.4\%) were having moderate type retinopathy on fundoscopy examination while 14(15.6\%) had nonproliferative diabetic retinopathy. Furthermore, patients were evaluated for tear meniscus height. Majority 45(50\%) had thin tear meniscus height while 11(12.25) had absent tear meniscus height as per the criteria mentioned earlier in this paper (table 3). Similarly, the findings of schimer's test have been mentioned in table 4 which have classified dryness in eyes. In our study, a total of 47(52.2\%) patients had dry eyes which was further classified into mild 21(23.3\%), moderate $16(17.8 \%)$ and severe 10(11.1) while tear film break up time distribution among the studied samples. Larger number of patients had low tear film breakup time as mentioned in (Table $5 \& 6$ ). 
Table 1: Sociodemographic characteristics of the studied sample

\begin{tabular}{|l|c|c|c|}
\hline Variables & & Frequency (n=90) & Percentage (\%) \\
\hline \multirow{4}{*}{ Age in Years } & $40-50$ & 16 & 17.8 \\
& $51-60$ & 22 & 24.5 \\
& $61-70$ & 31 & 34.5 \\
& 71 \& above & 21 & 23.2 \\
\hline \multirow{4}{*}{ Sex Distribution } & Male & 41 & 45.6 \\
& Female & 49 & 54.4 \\
\hline \multirow{5}{*}{ Occupation } & Professionals & 6 & 6.7 \\
& Associate professionals & 11 & 12.2 \\
& Skilled Workers & 23 & 25.5 \\
& Elementary occupation & 36 & 40.0 \\
& Unemployed & 14 & 15.6 \\
\hline \multirow{5}{*}{ Educational Status } & Honors & 6 & 6.8 \\
& Graduate & 11 & 12.2 \\
& Intermediate/Diploma & 42 & 46.6 \\
& High School & 22 & 24.4 \\
Socioeconomic & Illiterate & 9 & 10.0 \\
\hline & Upper (I) & 13 & 14.4 \\
& Upper Middle (II) & 34 & 37.8 \\
& Lower middle (III) & 26 & 28.9 \\
& Upper Lower (IV) & 15 & 16.7 \\
\hline
\end{tabular}

Table 2: Funduscopy findings of the studied sample

\begin{tabular}{|l|c|c|}
\hline Fundus Finding & $\begin{array}{c}\text { Frequency } \\
(\mathbf{n})\end{array}$ & $\begin{array}{c}\text { Percentage } \\
(\mathbf{\%})\end{array}$ \\
\hline No retinopathy & 32 & 35.5 \\
\hline Mild & 12 & 13.4 \\
\hline Moderate & 31 & 34.4 \\
\hline Severe NPDR & 14 & 15.6 \\
\hline PDR & 1 & 1.1 \\
\hline Total & $\mathbf{9 0}$ & $\mathbf{1 0 0}$ \\
\hline
\end{tabular}

Table 3: Tear Meniscus Height in the studied sample

\begin{tabular}{|l|c|c|}
\hline $\begin{array}{l}\text { Tear Meniscus } \\
\text { Height }\end{array}$ & $\begin{array}{c}\text { Frequency } \\
(\mathbf{n})\end{array}$ & $\begin{array}{c}\text { Percentage } \\
(\mathbf{\%})\end{array}$ \\
\hline Absent & 11 & 12.2 \\
\hline Normal & 34 & 37.8 \\
\hline Thin & 45 & 50.0 \\
\hline Total & $\mathbf{9 0}$ & $\mathbf{1 0 0}$ \\
\hline
\end{tabular}

Table 4: Schimer's test result in the studied sample

\begin{tabular}{|l|c|c|}
\hline Schirmer's test & $\begin{array}{c}\text { Frequency } \\
(\mathbf{n})\end{array}$ & $\begin{array}{c}\text { Percentage } \\
(\mathbf{\%})\end{array}$ \\
\hline Normal & 43 & 47.8 \\
\hline Mild & 21 & 23.3 \\
\hline Moderate & 16 & 17.8 \\
\hline Severe & 10 & 11.1 \\
\hline Total & $\mathbf{9 0}$ & $\mathbf{1 0 0}$ \\
\hline
\end{tabular}

Table 5: Prevalence of dry eye in the studied sample

\begin{tabular}{|l|c|c|}
\hline Dry eye & Frequency (n) & Percentage (\%) \\
\hline Present & 47 & 52.2 \\
\hline Absent & 43 & 47.8 \\
\hline Total & $\mathbf{9 0}$ & $\mathbf{1 0 0}$ \\
\hline
\end{tabular}

Table 6: Tear film break up Time in the studied patients

\begin{tabular}{|l|c|c|}
\hline $\begin{array}{l}\text { Tear film } \\
\text { breakup Time }\end{array}$ & $\begin{array}{c}\text { Frequency } \\
(\mathbf{n})\end{array}$ & $\begin{array}{c}\text { Percentage } \\
(\boldsymbol{\%})\end{array}$ \\
\hline Low & 47 & 52.2 \\
\hline Normal & 43 & 47.8 \\
\hline Total & $\mathbf{9 0}$ & $\mathbf{1 0 0}$ \\
\hline
\end{tabular}

\section{Discussion}

The study was conducted among individuals living with Type 2 diabetes mellitus who attended the out-patient unit of postgraduate department of ophthalmology, Government medical college and associated SMHS hospital for any eye ailment with an aim to examine the prevalence and clinical characteristics of DED.

In our study the prevalence of DED was estimated to be $52.2 \%$ among the studies individuals. The diagnosis of DED was done based on patient's symptoms, recognition of tear film stability, schimer's test and local ocular damage. In our 
study we observed that large number of studied patients had no symptoms and signs of local ocular damage but had abnormal funduscopy findings, tear meniscus height and schimer's test. Most of the previous studies have reported the prevalence of DED in the range of $20-70 \%{ }^{[4,10-}$ ${ }^{13]}$. The findings of our study are in accordance with the already published literature.

In our study, the age of the patients was in the age ranges of 40-79 years with mean age of $56 \pm 13.6$ years. Larger proportion of the studied patients (34.5\%) were in the age group of 61-70 years. Moreover, $49(54.4 \%)$ of the studied patients were females. These findings are in accordance with other studies published earlier ${ }^{[14-17]}$.

Each patient was evaluated and eye examinations were performed. The funduscopy findings of the studied patients is described in table 2. Among the patients 31 (34.4\%) were having moderate type retinopathy on fundoscopy examination while $14(15.6 \%)$ had non-proliferative diabetic retinopathy. Nepp et al ${ }^{[18]}$ were able to correlate the severity of retinopathy with the severity of dry eyes. K. Yoon et al. ${ }^{[19]}$, suggest that poor metabolic control, presence of DR stages is risk factors for tear film and ocular surface disorder in individuals with diabetes mellitus. Furthermore, patients were evaluated for tear meniscus height. Majority 45(50\%) had thin tear meniscus height while 11(12.25) had absent tear meniscus height.A study done by Whitcher et al ${ }^{[20]}$ found a scanty or absent tear meniscus is an indication of aqueous tear deficiency. In this study, TMH was thin in 50\% and absent in $12.2 \%$ studies patients. The finding are in accordance with the already reported studies by Whitcger et al ${ }^{[20]}$ and Uma Devi RS et al ${ }^{[4]}$. Tear film breakup time issupposed to be a diagnostic technique in detecting mucin deficient dry eye. Sukul et al. found the mean value of TBUT to be $9.67 \mathrm{~s}$ in the Indian populations. Similarly, the findings of schimer's test have been mentioned in table 4 which have classified dryness in eyes. In our study, a total of $47(52.2 \%)$ patients had dry eyes which was further classified into mild 21(23.3\%), moderate
$16(17.8 \%)$ and severe $10(11.1 \%)$. Lin et al. ${ }^{[21]}$ study showed the SchT was shown to be incapable of detecting meibomian gland disease. However, a low Schirmer result $(62.5 \%)$ was significantly associated with dry eye symptoms in this elderly Chinese population. The total tears secretion measured by Schirmer test was $>10 \mathrm{~mm}$ in $11.1 \%$ while between $5-10 \mathrm{~mm}$ was $17.8 \%$.

\section{Conclusion}

Dry eye disease is a common entity among individuals with diabetes mellitus. The estimated prevalence of DED at our hospital is about 52\% which is worrisome and needs early identification and treatment to reduce morbidity among patients.

\section{References}

1. Chen L, Magliano DJ, Zimmet PZ. The worldwide epidemiology of type 2 diabetes mellitus-present and future perspectives.Nat Rev Endocrinol.2012; 8:228-36.

2. X. Zou, L. Lu, Y. Xu, J. Zhu, J. He, B. Zhang, H. Zou, Prevalence and clinical characteristics of dry eye disease in community-based type 2 diabetic patients : the Beixinjing eye study, BMC Ophthalmol. 18 (2018) 1-7.

3. Lemp MA, Foulks GN. The definition and classification of dry eye disease:Report of the definition and classification subcommittee of the international dry eye workshop (2007). Ocul Surf. 2007;5:7592.

4. Devi RSU, Gowda MSS. Dry Eye in Diabetes Mellitus Patients and its Relationship with Diabetic Retinopathy. Int J Sci Stud 2016;4(8):67-72.

5. Dogru M, Katakami C, Inoue M. Tear function and ocular surface changes in noninsulin-dependent diabetes mellitus. Ophthalmology. 2001;108:586-92.

6. Jin J, Chen LH, Liu XL, Jin GS, Lou SX, Fang FN. Tear film function in non-insulin 
dependent diabetics [in Chinese]. Zhong Hua Yan KeZaZhi. 2003;39:10-3.

7. Manaviat MR, Rashidi M, AfkhamiArdekani M, Shoja MR. Prevalence of dry eye syndrome and diabetic retinopathy in type 2 diabetic patients. BMC Ophthalmol. 2008;8:10.

8. Najafi L, Malek M, Valojerdi AE, Aghili R, Khamseh ME, Fallah AE, et al. Dry eye and its correlation to diabetes microvascular complications in people with type 2 diabetes mellitus. J Diabetes Complicat. 2013;27:459-62

9. S. Mohd Saleem, Modified Kuppuswamy socioeconomic scale updated for the year 2019, Indian J. Forensic Community Med. 6 (2019) 1-3. doi:10.18231/23946776.2019.0001.

10. Ayaki M, Kawashima M, Negishi K, Kishimoto T, Mimura M, Tsubota K. Sleep and mood disorders in women with dry eye disease. Sci Rep. 2016;6:35276.

11. Wilkinson CP, Ferris FL 3rd, Klein RE, Lee PP, Agardh CD, Davis M, etal. Proposed international clinical diabetic retinopathy and diabetic macular edema disease severity scales. Ophthalmology. 2003; 110:1677-82.

12. Li J, Zheng K, Deng Z, Zheng J, Ma H, Sun L, et al. Prevalence and risk factors of dry eye disease among a hospital-based population in Southeast China. Eye Contact Lens. 2015;41:44-50.

13. Jie Y, Xu L, Wu YY, Jonas JB. Prevalence of dry eye among adult Chinese in the Beijing eye study. Eye. 2009;23:688-93.

14. Le Q, Zhou X, Ge L, Wu L, Hong J, Xu J. Impact of dry eye syndrome on visionrelated quality of life in a non-clinic-based general population. BMC Ophthalmol. 2012;12:22.
15. Cousen P, Cackett P, Bennett H, Swa K, Dhillon B. Tear production and corneal sensitivity in diabetes.JDiab Complications.2007;21:371-3.

16. Figueroa-Ortiz LC, Jime' nezRodr1'guez E, Garc1'a-Ben A,García-Campos J.Study of tear function and the conjunctival surface in diabetic patients. Arch Soc Esp Oftalmol 2011;86:107-112.

17. Song XJ, Li DQ, Farley W, Luo LH, Heuckeroth RO, Milbrandt $J$, et al. Neurturin-deficient mice develop dry eye and keratoconjunctivitissicca. Invest Ophthalmol Vis Sci. 2003;44:4223-9.

18. Nepp J, Abela C, Polzer I, Derbolav A, Wedrich A. Is there a correlation between the severity of diabetic retinopathy and keratoconjunctivitissicca? Cornea 2000;19:487-91.

19. K. Yoon, S. Im, M. Seo, Changes of Tear Film and Ocular Surface in Diabetes Mellitus, Korean J Ophthalmol. 18 (2004) 168-174.

20. Whitcher JP. Clinical diagnosis of the dry eye. IntOphthalmol Clin 1987;27:7-24.20.

21. Lin PY, Tsai SY, Cheng CY, Liu JH, Chou P, Hsu WM. Prevalence of dry eye among an elderly Chinese population in Taiwan: The shihpai eye study. Ophthalmology 2003;110:1096-101. 